\title{
A carga tributária e o Estado Social ${ }^{1}$
}

\section{Edison Rui Jóia ${ }^{2}$ \\ Marlene Kempfer Bassoli ${ }^{3}$}

\section{Resumo}

0 estudo apresenta aspectos da passagem do Estado Liberal para o Estado Social e as causas que contribuíram para essa mudança. 0 objetivo é de promover relações com estudos filosófico-políticos diante do modelo de Estado brasileiro registrado em nível constitucional, a carga fiscal e políticas públicas. Destaca a redemocratização do País e a elaboração da Constituição de 1988, destacando para o presente estudo a preocupação dos constituintes com a determinação de diretrizes para políticas públicas voltadas à redução da pobreza e das desigualdades sociais. Avalia que a efetivação desses direitos sociais está impactando as finanças públicas e, em consequência, impondo uma carga tributária mais elevada que o desejável, bem como reduzindo a capacidade de investimento do Estado brasileiro em áreas de estrutura básica que possibilitem o desenvolvimento econômico. Quer-se demonstrar o desafio dos governos diante das políticas públicas inseridas no texto constitucional brasileiro e a estrutura tributária que aponta para a manutenção da carga tributária em níveis elevados.

Palavras-Chave: Carga tributária; Estado Social; Políticas públicas.

\section{Introdução}

O Estado, como ente político, foi criado para atender ao bem comum, em especial às questões relacionadas às necessidades de sobrevivência e segurança de seus cidadãos, das quais derivaram uma série de atribuições de sua exclusiva competência. Para financiá-las é necessário instituir e arrecadar tributos.

Atualmente, há uma permanente discussão a respeito do tamanho da carga tributária. Preocupa-se com tema pois diante da globalização da economia é preciso que o mercado nacional seja economicamente competitivo e este objetivo se trona mais difícil de ser alcançado face aos custos de produção onde se computa o custo da tributação.

\footnotetext{
${ }^{1}$ Artigo extraído do Trabalho de Conclusão de Curso (TCC) sob orientação da Profa Drạ Marlene Kempfer Bassoli

${ }^{2}$ Bacharelando em Direito pela Universidade Estadual de Londrina - UEL .

${ }^{3}$ Doutora em Direito do Estado pela PUC/SP, Professora da graduação e pós-graduação da UEL, PUC-Londrina e UNIM AR-SP
} 
Como no resto do mundo, no Brasil a discussão a respeito da carga tributária é freqüente no noticiário econômico e na agenda política em todos os níveis de governo, cujo percentual aproximou-se, em 2007, dos $38 \%$ do PIB.

Diante deste quadro, a sociedade brasileira encontra-se frente a várias questões, e dentre elas seu principal dilema, que é o de tentar reduzir a carga tributária, para tornar sua economia mais competitiva, sem comprometer as políticas públicas que visam a redução das desigualdades sociais.

O propósito deste trabalho é demonstrar que a carga tributária guarda estreita relação com os compromissos sociais a que o Estado brasileiro está obrigado face às políticas públicas previstas em seu ordenamento jurídico.

\section{Do liberalismo ao estado social}

O Estado, como ente político, foi criado pelas comunidades primitivas para atender ao bem comum e nasceu da dissolução da sociedade primitiva fundada sobre laços de parentesco e da formação de comunidades mais amplas derivadas da união de vários grupos familiares por razões de sobrevivência interna (o sustento) e externas (a defesa) (BOBBIO, 2003, p. 73).

O Estado de direito pode ser sistematizado como portador das seguintes estruturas (BOBBIO, 2003, p. 401)

a) estrutura formal do sistema jurídico, que visa a garantia das liberdades fundamentais com a aplicação da lei geral-abstrata por parte de juízes independentes;

b) estrutura material do sistema jurídico: liberdade de concorrência no mercado, reconhecida no comércio aos sujeitos da propriedade;

c) estrutura social do sistema jurídico: a questão social e as políticas reformistas de integração da classe trabalhadora;

d) estrutura política do sistema jurídico: separação e distribuição do poder. 


\section{O Estado liberal}

A passagem da forma feudal da produção econômica para o capitalismo deu-se de forma lenta e gradual entre os Estados absolutistas então predominantes na Europa. Ainda em sua versão absolutista, o Estado Moderno desenvolveu-se a partir do surgimento de uma burguesia capitalista originada das novas formas de produção econômica. Essa burguesia firmou-se como um novo integrante na sociedade existente.

Com a Revolução Francesa, a conquista do poder pela burguesia fez prevalecer uma nova ordem social com o triunfo do liberalismo, sem que isto, no entanto, conduzisse a França ao estágio de democracia, pois ainda prevalecia a manutenção de privilégios e discriminações. Esta foi a grande frustração popular da França pós-revolução, pois os princípios liberais-democráticos que nortearam a Revolução e foram base para a Constituição de 1893, não foram aplicados na prática a toda população. Ficou claro que não se poderia confundir liberalismo com democracia, ou simplesmente colocá-los numa relação de causa e efeito, já que não são interdependentes, ainda que estejam íntima e historicamente ligados (BONAVIDES, 2004, p. 42-43).

Ainda que a Revolução Francesa tenha frustrado a população quanto aos resultados, seu acontecimento despertou no povo a consciência de luta por suas liberdades políticas. Passou a ser um ideal que todas as classes sociais pudessem participar do governo, por meio da soberania popular e da representação e com a separação dos poderes.

O modelo liberal pode ser apresentado a partir de seus distintos núcleos (STRECK, 2003, p. 53-55):

a) núcleo moral - Contém uma afirmação de valores e direitos básicos atribuíveis à natureza do ser humano, que são as liberdades individuais de pensamento, expressão, crença, etc;

b) núcleo político - Neste núcleo estão presentes os direitos políticos, que se apresentam sob quatro aspectos: a) consentimento individual; b) representação; c) constitucionalismo: a garantia dos direitos fundamentais do indivíduo e os limites do poder político estão estabelecidos em um documento fundamental; d) soberania popular. 
c) núcleo econômico - 0 modelo econômico liberal tem seus pilares na propriedade privada e em uma economia de mercado livre de controle estatal em que, para o liberalismo, o mercado se auto-regula por meio da livre iniciativa e da competição, o que por si só traria ordem e riqueza aos interesses concorrentes.

Para Norberto Bobbio (1988, p. 17), "o liberalismo é uma determinada concepção de Estado, na qual o Estado tem poderes limitados, e como tal se contrapõe tanto ao Estado absoluto quanto ao Estado que hoje chamamos de social".

Com o liberalismo, o poder estatal, antes absoluto, além de sofrer divisão, passou a poder atuar de modo limitado, ou seja, para a defesa dos valores voltados para o indivíduo e não para a comunidade: liberdade individual, propriedade privada, garantir paz e segurança.

\section{O Estado social}

Ao longo da história, o Estado, como ente político, em seu constante desenvolvimento, vem adquirindo funções variadas que se originam na própria complexidade das relações sociais .

Dentre as funções destacadas é possível incluir algumas que vieram a caracterizar 0 Estado Social, e que são formas de garantir a todo cidadão, não como caridade ou assistencialismo, mas como direito político, a garantia de uma renda mínima, o direito à alimentação, à saúde, à habitação e à educação. Como modelo de Estado social, Bobbio (2003, p. 416) cita o relatório "Beveridge", de 1942, ressaltando que: “[...] Na realidade, 0 que distingue o Estado assistencial de outros tipos de Estado não é tanto a intervenção direta das estruturas públicas na melhoria do nível de vida da população quanto 0 fato de que tal ação é reivindicada pelos cidadãos como um direito.

São dadas como causas principais desse processo de transformação do Estado Liberal em Estado Social (DALLARI, 2003, p. 63-64):

a) a Revolução Industrial e suas consequêencias de proletarização, urbanização e mudanças nas condições de trabalho, na previdência e na degradação ambiental;

b) a Primeira Guerra M undial que rompe a tradição do liberalismo econômico e traz a necessidade de controle integral e coativo da vida econômica e que se reflete na 
Revolução Russa, na Constituição de Weimar (1919) e no constitucionalismo social iniciado pela Constituição M exicana de 1917;

c) a crise econômica de 1929 e a Depressão trouxeram embutida a necessidade de intervenção na economia, atingindo a iniciativa privada por meio das ações governamentais em políticas sociais (Roosevelt e o New Deal);

d) a Segunda Guerra M undial que obriga o Estado a assumir um papel controlador dos recursos sociais, de modo a manter a produção e a distribuição dos bens produzidos, exercendo um controle da economia;

e) as crises cíclicas que apontava, já ao final do século, para as fissuras do liberalismo, que afetavam o comportamento da economia, também com a ação dos monopólios, num quadro em que aumentavam as desigualdades sociais, comprometendo a subsistência do sistema;

f) os movimentos sociais repudiam a idéia de que a livre força do mercado seria capaz de organizar o processo econômico, onde a livre concorrência é muitas vezes incompatível com o interesse social;

g) o surgimento de uma idéia de liberdade positivada pela incorporação das conquistas sociais.

A partir destas causas, o Estado que emerge passa a ter um compromisso de cumprir uma função social. Deixa de ser apenas um Estado em que a ação social se dá para exercer um assistencialismo baseado na caridade. Tem atribuição de intervir de modo que o desenvolvimento econômico tenha como objetivo o bem-estar de toda a sociedade e não apenas o de trazer benefícios aos poucos que detêm o controle dos meios de produção.

Compromissos da constituição da república federal e o estado social

A injustiça social que acomete a sociedade brasileira há séculos e que exclui parte significativa da população brasileira do acesso a condições mínimas de dignidade e cidadania causa perplexidade face à grandeza, em quantidade, em diversidade e em qualidade, de nossos recursos naturais.

A Nova Carta foi escrita num momento em que as questões relativas à pobreza, a desigualdade, a marginalização, o nosso subdesenvolvimento passaram a dominar a agenda 
política do País recém-democratizado. Era anseio geral a definição de metas de desenvolvimento que visasse uma sociedade mais justa, que criasse as bases para o desenvolvimento social, econômico, político, ético e cultural.

A Constituição Federal de 1988 prevê um conjunto de direitos e garantias sociais típicos de um Estado Social. Prevê, em seu Art. 3o, inciso III: "erradicar a pobreza e a marginalização e reduzir as desigualdades sociais e regionais". O que é, antes de tudo, é um reconhecimento oficial da existência da pobreza, da marginalização e das desigualdades regionais, definindo que é um objetivo fundamental da República por um fim nessa situação. Este reconhecimento gerou outros dispositivos que visam da efetividade a esse objetivo, como os descritos no Título VIII - Da Ordem Social - da Constituição Federal, que contém as diretrizes fundamentais de políticas públicas voltadas para atender às necessidades da saúde, previdência e assistência social.

A inclusão desses objetivos na Nova Carta bem como das demais normas que dele derivam sofreu uma série de críticas por parte dos mais variados setores da economia, sob a alegação que isto tornaria o País ingovernável face à inevitável elevação do gasto público.

A elevação do déficit público decorrente dos novos compromissos constitucionais de cunho social era inevitável, mas não foi a única causa da piora das contas públicas, que tem uma dupla interpretação (GIAMBIAGI, 2000, p. 172):

a) A primeira, que como em qualquer país, as ações de um governo decorrem do jogo de forças interno entre as autoridades econômicas, de um lado - interessadas em praticar políticas fiscais austeras - e as lideranças políticas, de outro - voltadas para a satisfação das demandas, independentemente da existência de fontes de financiamento.

b) A segunda - que é complementar à primeira - é que o governo, mais preocupado, de curto prazo em saldar pelo menos parte da chamada "dívida social", optou por elevar o gasto, julgando que, no médio prazo, num contexto de um processo de crescimento sustentado da economia, a expansão da despesa poderia ser depois contida, ao mesmo tempo em que a receita acompanharia o PIB, o que diminuiria progressivamente o déficit público e faria do aumento da dívida um fenômeno temporário. 
A Constituição de 1988 impôs aos Governos e à sociedade novos compromissos, o que aumentou o gasto público. No entanto, não se pode atribuir a esses compromissos todo o desequilíbrio nas contas públicas. É visível que tem faltado aos Governos uma maior disciplina nos gastos públicos, pois eles cresceram também em setores que não podem ser considerados prioridades nos termos constitucionais. Constata-se que o novo Estado erigido em 1988 não implicou necessariamente em mudança de hábito dos gestores públicos.

\section{0 regime tributário de 1988 e seu caráter federativo}

O Brasil assumiu a forma de Estado Federal com a proclamação da República, em 15 de novembro de 1889 , que vem sendo mantida desde então, ainda que tenha sido apenas nominal nos períodos de ditadura.

É importante salientar que a Constituição Federal/88 coloca a União, os Estados, os Municípios e o Distrito Federal em idêntico plano, respeitados o papel definido para cada um. Entre os elementos básicos do modelo federal tem-se autonomia administrativa, financeira, política e, neste caso, decidir sobre as atribuições impostas pela Constituição bem como sobre a competência tributária.

No Brasil, a competência para instituir e cobrar tributos deve ser exercida por meio da lei. Assim, a função estatal de tributar está organizada num sistema de competências disciplinado pelo ordenamento jurídico, e é a Constituição Federal quem dá aptidão e limite aos entes federados para criar os tributos em sua esfera de competência, o que a torna a lei tributária fundamental (CARRAZA, 2007, p. 124-141).

Com a proclamação da República em 1889, o sistema tributário, herdado do Império, permaneceu praticamente incólume até os anos 1930. Poucas mudanças foram introduzidas até a Constituição de 1934. Na época do Império a economia era basicamente agrícola e a principal fonte dos tributos era o comércio exterior.

A Constituição de 1934 introduziu diversas modificações, principalmente, para os Estados e Municípios e os impostos internos sobre produtos passaram a predominar. Aos Estados foi atribuída a competência para tributar as vendas e consignações, ao mesmo tempo em que se proibiu o imposto de exportações em transações interestaduais. Os tributos de competência dos Municípios eram, entre outros, o imposto predial e territorial 
urbano, o imposto sobre diversões públicas, o imposto sobre a renda de imóveis rurais e as taxas sobre serviços municipais.

Nos anos 1960 diversas modificações foram introduzidas com o objetivo de aumentar a capacidade de arrecadação do Estado e solucionar o problema do déficit fiscal.

Com as diversas reformulações, ocorridas principalmente em reformas entre 1965 e 1967, já durante o Regime Militar, no sistema tributário então vigente, os impostos passaram a ser classificados nas seguintes categorias (GIAM BIAGI, 2000, p. 243):

a) impostos sobre comércio exterior: os impostos de importação e de exportação, este último, anteriormente estadual;

b) imposto sobre o patrimônio e a renda: neste grupo foram reunidos o imposto predial e territorial urbano (municipal), o imposto de transferência de bens imóveis (estadual) e o imposto territorial rural e o imposto de renda (união);

c) impostos sobre a produção e a circulação: neste grupo estavam o IPI (união), 0 ICM S (estadual), o imposto sobre serviço de transportes e comunicações (estadual), o imposto sobre operações financeiras (união) e o imposto sobre serviços (municipal);

d) impostos únicos: sobre a energia elétrica, sobre combustíveis e lubrificantes e sobre minerais, todos na esfera da união;

e) receitas extra-orçamentárias: neste grupo estavam incluídos a contribuição do empregador para o fundo de garantia por tempo de serviço e as contribuições para a Previdência Social.

Com a vigência da Constituição de 1988, o Governo Federal, sem condições políticas e técnicas de reduzir os custos de imediato para fazer frente ao desequilíbrio fiscal e financeiro, adotou sucessivas medidas para compensar suas perdas, que pioraram a qualidade da tributação e dos serviços prestados.

Na área tributária ocorreu a criação de novos tributos e elevação das alíquotas dos já existentes, em particular daqueles não sujeitos à partilha com Estados e Municípios: a Contribuição incidente sobre o Lucro Líquido das empresas (1989); o aumento da alíquota da 
COFINS de 0,5\% para 2\%; e, também, das do imposto sobre operações financeiras (1990); e a criação do Imposto Provisório sobre M ovimentações Financeiras (1993).

Em conseqüência dessa nova ordem tributária, ocorreu uma queda na qualidade do sistema tributário sem contribuir para um equacionamento definitivo de seu desequilíbrio financeiro e fiscal, comprometendo a ação do governo federal nas áreas sociais, enquanto 0 fortalecimento financeiro dos Estados e Municípios, apesar de significativo, tem sido insuficiente para atender às ampliadas demandas sociais.

Com o aumento das transferências tributárias, introduzidas pela Constituição de 1988, houve uma redução nos recursos disponíveis da União. Ante à necessidade de compensar a perda de receita, o Governo Federal agiu como de costume, aumentando tributos (GIAM BIAGI, 2000, p. 254-255).

A Constituição de 1988 não trouxe grandes modificações à estrutura tributária herdada do Regime Militar. 0 que houve de maior impacto foi um acentuado incremento nas transferências tributárias em detrimento da União. Esta, por sua vez, ao corrigir esta situação optou por instituir tributos não transferíveis, uma vez que visava solucionar seu crônico problema de déficit fiscal.

\section{Evolução da carga tributária}

Para que o Estado possa executar adequadamente as suas funções ele necessita de recursos que são obtidos por meio de uma política fiscal.

A política fiscal abrange três funções básicas: a) função alocativa diz respeito ao fornecimento de bens públicos; b) função distributiva, por sua vez está associada a ajustes na distribuição de renda que permitam que a distribuição prevalecente seja aquela considerada justa pela sociedade; c) função estabilizadora tem como objetivo o uso da política econômica visando um alto nível de emprego, à estabilidade dos preços e à obtenção de uma taxa apropriada de crescimento econômico (GIAM BIAGI, 2000, p. 30).

É dessa política fiscal que se originam os tributos devidos pela sociedade ao Estado. Ao valor total dos tributos arrecadados em um dado período em relação ao valor total dos bens produzidos nesse mesmo período dá-se o nome de carga tributária, que pode ser definida como sendo a proporção entre a quantidade de riqueza produzida no país e o que 0 governo arrecada em impostos, taxas e contribuições. 
A evolução da carga tributária coincide com a entrada do Brasil no ciclo de industrialização e a conseqüente urbanização do País. Tomando como ponto de partida o período que se inicia após a redemocratização de 1946, encontrando-se o seguinte quadro (GIAM BIAGI, 2000, pp. 246-247):

a) de 1946 a 1958, a carga tributária registrou um crescimento lento, passando de $13,8 \%$ a $18,7 \%$ do PIB;

b) com a crise econômica do início dos anos 1960, houve uma redução da carga tributária que chegou recuar para $15,8 \%$ do PIB;

c) com a reforma dos anos 1960, foi criado um sistema tributário que, apesar da falta de eqüidade e do alto grau de centralização, era tecnicamente avançado para a época, mas com mudanças que causaram uma elevação da carga tributária para $\mathbf{2 5 \%}$ do PIB, permanecendo neste patamar no final dos anos 1960 e durante toda década de 1980;

d) ao longo dos anos 1980, face à recessão econômica do início da década, uma série de alterações na legislação foram introduzidas com o propósito de manter a carga tributária nos níveis anteriores, face à crescente queda na arrecadação. Na segunda metade da década ela oscilou em torno de $\mathbf{2 3} \%$ a $\mathbf{2 4 \%}$, exceção ao ano de $\mathbf{1 9 8 6}$, no Plano Cruzado, em que atingiu a $\mathbf{2 7 \%}$ do PIB;

e) em 1990, após os ajustes do Plano Collor, quando chegou a $\mathbf{2 9} \%$ do PIB, retornou aos $25 \%$ do PIB, nível da década de 1980;

f) com a estabilização da economia, pelo Plano Real, e a aprovação de novas medidas destinadas a aumentar impostos, a carga tributária voltou a crescer, agora com maior intensidade, aproximando-se do nível de 30\% do PIB no final dos anos 1990.

A partir do ano 2000 a carga tributária, ainda que tenha oscilado um ou outro ano, tem sido crescente, tendo atingido 37\% do PIB em 2007.

A carga brasileira equivale à média dos países mais ricos, muito acima das demais economias emergentes, sobretudo as latinas. Na divisão federativa, o Governo Federal, com as contribuições, voltou a centralizar geração de tributos e, em 2006, respondia sozinho por $68,4 \%$ da arrecadação nacional. A descentralização, entretanto, é mantida com a repartição 
constitucional de receitas - a participação federal fica perto de 58\%, a dos Estados em torno de $25 \%$, cabendo aos Municípios 17,2\% da receita global.

\section{Das políticas públicas do estado social brasileiro e seu financiamento}

O maior desafio do Brasil redemocratizado será por muito tempo a eliminação da miséria e a redução das desigualdades sociais. O Texto Constitucional de 1988 impõem aos Governos compromissos para garantir que a busca de solução para os graves problemas sociais não mais será postergada. Para tal obrigação deve-se formular e executar políticas públicas, ou seja, ações governamentais que visam atingir objetivos na área social, ou seja, são projetos que se constituem em instrumentos de ação do Estado por meio dos governos.

No Brasil, principalmente a partir da Constituição de 1988, as políticas públicas vêm deixando, aos poucos, de ser apenas um conjunto de promessas vazias de políticos em campanha para tornarem-se direitos positivados no ordenamento jurídico. Sendo assim, deve-se abandonar a ideologia liberal do assistencialismo e passar para a interpretação de direitos e deveres de cidadania.

O Art. 23 da Constituição Federal - Título III - Da Organização do Estado determina que é de competência comum da União, dos Estados, do Distrito Federal e dos M unicípios, várias funções, e, dentre elas, merece destaque o inciso X: "combater as causas da pobreza e os fatores de marginalização, promovendo a integração social dos setores desfavorecidos". Em complemento, os Art. 79 a 82 do ADCT - Ato das Disposições Constitucionais Transitórias, em conjunto com a Lei Complementar no 111, de 06 de julho de 2001, definem as fontes de financiamento do Fundo de Combate e Erradicação da Pobreza.

No texto do referido artigo vê-se aplicado o princípio federativo no que diz respeito à distribuição de competências e 0 estabelecimento de políticas públicas voltadas para 0 combate à pobreza. E, ao mesmo tempo em que define a fonte de financiamento dessas políticas, obriga os entes federados à concretização desses objetivos.

Na área da saúde, o Art. 23, inciso II, define também a competência comum dos entes federados para "cuidar da saúde e assistência pública, da proteção e garantia das pessoas portadoras de deficiência". Para esses compromissos, bem como para a educação, o legislador estabeleceu limites mínimos de investimento, instituindo a vinculação de receitas, como forma a forçar as ações do executivo para efetivação desses direitos. 
As políticas públicas, quando aprovadas pelos representantes do povo, dentro dos critérios da legalidade e da constitucionalidade, passam a integrar o ordenamento jurídico e por ele são garantidas e protegidas.

A execução das políticas públicas é uma necessidade social, não bastando apenas que constem do ordenamento jurídico, mas, sobretudo, no Brasil de hoje, será necessário que se tornem efetivas para que seus objetivos sejam alcançados. Para esse fim, estão sujeitas a diversos tipos de controle.

O Art. 74 da Constituição Federal determina que os Poderes Legislativo, Executivo e Judiciário manterão, de forma integrada, um sistema de controle interno que tem, entre outras finalidades, a função de avaliar o cumprimento das metas previstas no plano plurianual, a execução dos programas de governo e dos orçamentos da União, principalmente, no que diz respeito à eficácia e eficiência da gestão orçamentária.

Paralelamente ao controle interno, as políticas públicas estão sujeitas, também, ao controle externo. Além do controle social, frutos da participação popular, as políticas públicas, no campo institucional, passam a ser objeto do controle parlamentar direto, do controle pelos Tribunais de Contas e, principalmente, do controle jurisdicional.

Dessas modalidades de controle, a que vem despertando maior controvérsia é 0 controle judicial das políticas públicas, pois com freqüência o Poder Executivo critica decisões do Poder Judiciário que o obriga a cumpri-las.

Para Eduardo Appio (2005, p. 159), a legitimidade do Poder Judiciário está ligada aos objetivos do sistema representativo:

A intervenção judicial será mais pronunciada nos casos em que o governo eleito se distanciar dos programas inicialmente propostos, na medida em que o poder Judiciário gozará, nestes casos, de uma legitimidade material decorrente dos objetivos do próprio sistema representativo.

Num Estado Democrático de Direito, com um sistema representativo, os atos políticos são legitimados por meio de consenso, por menor que seja este, na esfera do Poder Legislativo.

A inserção de políticas públicas no texto constitucional, por si só, não tem sido suficiente para a efetivação dos direitos sociais que a tutela jurídica pretende alcançar, muito embora tenha sido uma conquista democrática de grande significado. 
Mesmo tendo decorrido duas décadas da promulgação do texto constitucional, o País enfrenta dificuldades na efetivação desses direitos sociais. Várias são as causas desse insucesso. A principal é, sem dúvida, a escassez de recursos, mas é também de grande significado a pouca educação do povo para a compreensão e defesas desses direitos e o grau de consolidação democrática, sobretudo, a cultura política e administrativa, presentes em nossas instituições, que são as responsáveis pela implementação dessas políticas públicas (BREUS, 2007, p. 202-235).

A partir da Constituição de 1988, a União, bem como os Estados e M unicípios, vem ampliando ano a ano os gastos na área social, com vistas a combater a miséria e reduzir as desigualdades sociais, conforme determina a Constituição Federal, tanto pela iniciativa dos governantes, quanto pela crescente busca de solução pela via judicial.

Essas obrigações do Estado vinculam e comprometem o orçamento público, por isso são vítimas freqüentes do discurso liberal que os vê como entrave ao desenvolvimento, uma vez que reduzem consideravelmente a capacidade do Estado em investimentos no setor produtivo.

Para o IPEA - Instituto de Pesquisa Econômica Aplicada - em estudo publicado em junho de 2006, sobre os gastos públicos, especialmente os de cunho social, do Governo Federal, do período de 1991 a 2005, as conclusões são as seguintes (IPEA, 2006, p. 93-94): "

a) redução do gasto discricionário: Houve redução dessas despesas (gastos com consumo dos ministérios) entre 2001 e 2005. Este tipo de gasto não é, ao que parece, vilão do crescimento dos gastos públicos;

b) crescimento dos gastos sociais: Houve, a partir de 2001, forte expansão dos gastos sociais, que passaram de 1,8\% do PIB em 2001 para 2,7\% do PIB em 2005.

c) crescimento da Previdência Social Básica (INSS): as despesas do INSS continuam pressionando o gasto primário federal. manutenção dos gastos com pessoal e outras despesas não-financeiras: os gastos com o pessoal ativo da União não têm crescido como proporção do PIB, o que demonstra que não é o gasto do atual governo federal com o pagamento do pessoal ativo que tem pressionado 0 gasto público. 
Observa-se que na questão da definição de políticas públicas, a partir da Constituição de 1988, a busca do cumprimento dos compromissos sociais constitucionais vem provocando um significativo crescimento dos gastos públicos, em especial as despesas com programas de combate à pobreza, com a Previdência e a Assistência Social, que em parte também vêm sendo utilizados como instrumentos de distribuição de renda. No entanto, outros antigos desafios também devem ser enfrentados: o investimento público em infra-estrutura para promover o desenvolvimento econômico. Somente com olhares para estas realidades devem-se julgar as questões sobre a legitimidade ou não da carga fiscal.

\section{Conclusão}

Ainda que nem sempre consiga cumprir adequadamente suas atribuições, a existência do Estado é imprescindível para a sobrevivência, segurança e desenvolvimento de uma sociedade,

Em sua evolução, teve o Estado, em seu modelo liberal, importância significativa nas conquistas das liberdades individuais e no desenvolvimento econômico de sua época. Em passo seguinte, coube ao chamado Estado Social, estabelecer e garantir condições mínimas para o provimento das necessidades por meio de conquistas sociais, especialmente, aos menos favorecidos.

A Constituição promulgada em 05 de outubro de 1988, em processo de redemocratização, traz aos governos o modelo de Estado Democrático de Direito que por si só implica em referências de importantes mudanças. No campo dos direitos sociais, estabeleceu e passou a garantir uma série de políticas públicas, nas áreas de educação, saúde, assistência e previdência social, redução das desigualdades sociais e regionais. Estes compromissos trouxeram sensíveis impactos ao orçamento público.

Por outro lado, a sociedade tem dificuldade em aceitar qualquer elevação da carga tributária, que era de $27 \%$ em 1989, logo após a Constituição ser promulgada, mas que já ultrapassou os 37\% do PIB em 2007.

Assim, os governos contemporâneos vivem o desafio de crescer economicamente, pagando duas enormes dívidas, financeira (dívida pública) e a social, e sem poder, no curto prazo, reduzir a carga tributária. 
A história mostra que foi difícil o caminho percorrido para a conquista de um Estado Democrático de Direito e que não será diferente o caminho do desenvolvimento sócioeconômico, por meio de políticas públicas emancipatórias.

\section{Referências}

APPIO, Eduardo. Controle Judicial das Políticas Públicas no Brasil. 22. ed. Curitiba: Juruá, 2005.

BREUS, Thiago Lima. Políticas públicas no Estado Constitucional: problemática da concretização dos Direitos Fundamentais pela Administração Pública brasileira contemporânea. 1. ed. Belo Horizonte: Fórum, 2007.

BOBBIO, Norberto. Estado Governo e Sociedade - Para uma teoria geral da política. 10. Edição. São Paulo: Paz e Terra. 2003. . Liberalismo e Democracia. São Paulo: Brasiliense, 1988.

BOBBIO, Norberto; M ATTEUCCI, Nicola; PASQUINO, Gianfranco. Dicionário de Política.. Brasília: UNB. 2003. v. 10.

BONAVIDES, Paulo. Do Estado Liberal ao Estado Social. 7. ed. São Paulo: M alheiros. 2004.

BUCCl, M aria Paula Dallari. Direito administrativo e políticas públicas. 1. ed. São Paulo: Saraiva, 2002.

CARRAZZA, Roque Antonio. Curso de Direito Constitucional Tributário. 23. ed. São Paulo: Malheiros. 2007.

GIAMBIAGI, Fábio e ALÉM , Ana Cláudia Duarte de. Finanças Públicas. 2. ed. Rio de Janeiro: Elsevier. 2000.

REFORM A Tributária. Disponível em:

«ttp://www.fazenda.gov.br/portugues/documentos/2008/fevereiro/Cartilha-ReformaTributaria.pdf>. Acesso em: 19 maio 2008.

IPEA. Boletim de Conjuntura: Expansão e Controle do Gasto Público Federal. N. 73. Rio de Janeiro: IPEA. 2006. . Políticas sociais: acompanhamento e análise. n. 9. Rio de Janeiro: IPEA. 2004. . Políticas sociais: acompanhamento e análise. n. 12. Rio de Janeiro: IPEA. 2006.

REZENDE, Fernando. Finanças Públicas. 2. ed. São Paulo: Atlas. 2007. 
STRECK, Lenio Luiz e M ORAES, José Luiz Bolzan de. Ciência Política e Teoria Geral do Estado.3. ed. Porto Alegre: Livraria do Advogado: 2003. 